\title{
ALTERNATIVE TO Q WAVE DIAGNOSIS USING CARDIAC ACTION POTENTIAL PROPAGATION TIME MEASUREMENT
}

\author{
Ananthi S. ${ }^{1}$, Vignesh V. ${ }^{1}$, Padmanabhan $\mathrm{K}^{2}$
}

The diagnosis of myocardial infarction is done by ECG through the observation of $Q$ waves in one or more leads. The paper describes the relationship between $Q$ waves and the propagation time of the Cardiac Action potential and a technique by which this time of propagation itself can be measured. Rather than observing the $Q$ wave pathology in its very small peak of the total QRS complex, a more refined method is thus made available for continuous patient observation. This propagation time rises from $15 \mathrm{~ms}$ to $35 \mathrm{~ms}$ or more in progressive pathological conditions. A simulation has been done which illustrates how the $Q$ wave is generated from the travelling action potential wave in the ventricle. The authors have utilized the easy to use novel EPIC Microelectrodes from Plessey Electronics, which are jelly free and provide easy attachment by simple skin contact. Multiple sensors were placed on the chest and the propagation time was measured by differential voltages between them. An embedded controller was used to pick these signals in digitized form and calculate the time intervals. The measurement procedure is simple and highly non invasive. Records from outpatients with cardiac pathology were taken and it was verified that this AP time increases with the $Q$ wave width. This AP propagation time is a more refined method of observing pathological changes than the $Q$ wave, since progressive changes in cardiac condition can be indicated by changes in the millisecond values. It has been verified that the values match with to the usual $Q$ wave width timings.
Russ J Cardiol 2016, 4 (132), Engl.: 179-186

http://dx.doi.org/10.15829/1560-4071-2016-4-eng-179-186

Key words: electrocardiogram, action potential, Q-wave, action potentia propagation time, EPIC sensor.

${ }^{1}$ University of Madras, Chennai; ${ }^{2}$ A.C. College of Technology, Anna University, Chennai, India.

Corresponding author. S. Ananthi, Associate Professor and Head of the Department of Information Technology, University of Madras. India. Email: ananthipradeep84@gmail.com, Telephone: 04422202767.

AP - action potential, APP - action potential propagation, $\mathrm{Ml}$ - myocardial infarction, ECG -electrocardiogram, STEMI - ST elevation with myocardial infarction, EPIC - electric potential integrated circuit, ADC - analog to digital converter, DSO - digital storage oscilloscope.

Received March 04, 2016.

Revision received March 21, 2016.

Accepted March 28, 2016.

\section{АЛЬТЕРНАТИВА ДИАГНОСТИКЕ Q-ВОЛНЫ С ИСПОЛЬЗОВАНИЕМ ИЗМЕРЕНИЯ ВРЕМЕНИ РАСПРОСТРАНЕНИЯ СЕРДЕЧНОГО ПОТЕНЦИАЛА}

Ananthi S., Vignesh V., Padmanabhan K.

Диагностика инфаркта миокарда проводится с помощью ЭКГ через наблюдения Q-волны в одном или более отведениях. Рассмотрена взаимосвязь между Q-волнами и временем распространения сердечного потенциала и метод, с помощью которого это распространение может быть измерено. Вместо того чтобы наблюдать патологию Q-волны в ее самой маленькой точке возвышения во всем комплексе QRS, становится доступным более современный метод для непрерывного наблюдения за пациентом. Это время распространения поднимается от 15 мс до 35 мс или более при развивающихся патологических состояниях. Совершенное моделирование показано, как Q-волна генерируется из блуждающего потенциала действия волны в желудочке. Авторы использовали простой в использовании современный EPIC микроэлектрод производства Plessey Electronics, который не требует лубрикатора и обеспечивает легкое крепление путем простого контакта с кожей. Многочисленные датчики были размещены на груди и время прохождения измерялось с помощью дифференциального напряжения между ними. Встроенный контроллер использовался, чтобы фиксировать эти сигналы в цифровом виде и вычислять интервалы времени. Процедура измере-

The recording of ECG in cardiac care uses the externally placed electrode differential potentials. The heart's ventricular contraction is due to the conducting nerve impulse from the Atrio Ventricular node to the entire ventricular volume. This internal potential is known as the "Action Potential" (AP) [1] and this propagates through the ventricle in each heart beat. It has a sharp rise $(<20 \mathrm{~ms})$, a plateau period $(0,4-0,6 \mathrm{~s})$ and a droop time $(0,2-0,4 \mathrm{~s})$ back to the resting potential and is about $100 \mathrm{mV}$ is amplitude. ния проста и весьма неинвазивная. Были использованы записи амбулаторных больных с кардиальной патологией и выяснилось, что этот потенциал действия возрастает с шириной Q-волны. Этот метод распространения потенциала действия является наиболее усовершенствованным методом наблюдения патологических изменений Q-волны, поскольку прогрессивные изменения в состоянии кардиологического больного могут быть отмечены путем изменения значения миллисекунд. Было проверено, что полученные значения совпадают с обычной шириной Q-волны.

Российский кардиологический журнал 2016, 4 (132), Англ.: 179-186 http://dx.doi.org/10.15829/1560-4071-2016-4-eng-179-186

Ключевые слова: ЭКГ, потенциал действия, Q-волна, время распространения потенциала действия, датчик EPIC.

${ }^{1}$ University of Madras, Chennai; ${ }^{2}$ A.C. College of Technology, Anna University, Chennai, Индия.

Time measurements on a full ECG of a heartbeat have been made in several ways and even automatic analysis of variations attempted [2]. However, what we deal with in this paper is the time of AP propagation, which is initiating the compression of the ventricle.

The effect of a traveling wave of this action potential is seen as the familiar ECG waveform. In it, the QRS complex is a representation of the rising AP. Several models for QRS complex estimation have also been reported as signal processing exercises [3]. 
The propagation of the action potential impulse through the ventricle is via nexus or gap junctions $[1,4]$ and the specific subcellular distribution of the gap junctions packed by rod shaped cardio myocytes causes continuous conduction [5]. In a pathological condition, the substrate associated with Myocardial infarction (MI) contains islands of surviving myocardium interconnected by narrowed strands with reduced coupling through nexus junctions. In diseased heart, structural non homogeneities are present [6] which cause delay in the AP Propagation. Assessment of myocardial injury is indicated by the external ECG waveforms through Q wave changes (Figure 1), T wave abnormality, ST deviation present long after a MI and so on. Myocardial infarction recognized through just ST elevation (STEMI) is not very decisive in assessing MI and methods of vector cardiography alone could detect delays in AP propagation [7].

$\mathrm{Q}$ waves with amplitude more than one fourth of the $\mathrm{R}$ wave in Einthoven and Wilson leads are taken as pathological. It is stated [8] that patients with Q wave MI had worse prognosis compared to those without Q wave MI and hence warrant a closer follow up. The presently observed $\mathrm{Q}$ wave diagnosis relies on the small segment within 1 to 2 squares in the ECG record (Figure 1). Time measurements based on the width and half height of the Q wave vary from 15 to 35 or even $40 \mathrm{~ms}$ in MI. It is stated that a mere presence or absence of a $\mathrm{Q}$ wave greater than $30 \mathrm{~ms}$ in duration may lead to "correct" diagnosis of infarction or not in $79 \%$ of trials.

The genesis of the $\mathrm{Q}$ wave has been simulated as due to the propagation delay of the cardiac action potential wave. Any interim delay in the ventricular fibers will cause a $\mathrm{Q}$ wave to appear on the externally recorded ECG electrodes.

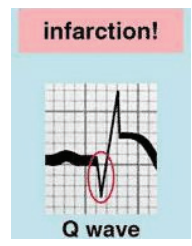

Figure 1. $Q$ waves in a ECG record is significant in myocardial pathology.

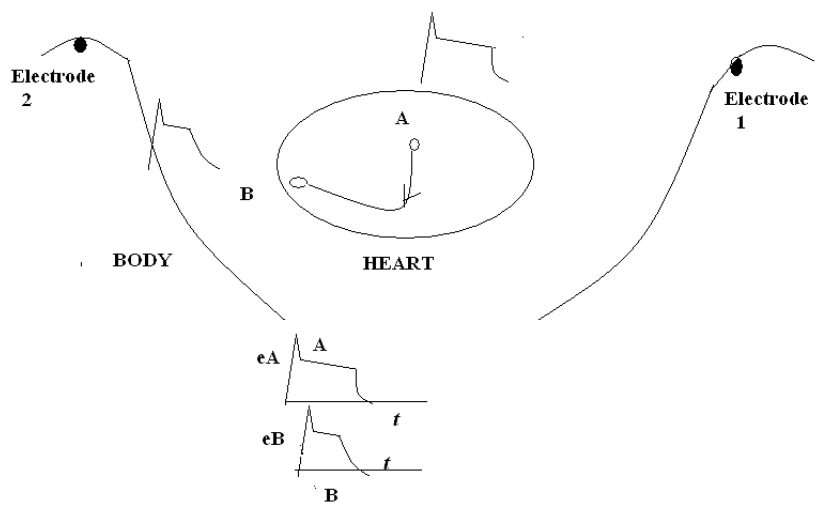

Figure 2. Showing the waveforms in the Ventricular fibers reaching the electrodes on the body surface.
This fact has been verified by simulating a propagating action potential wave and its effect on the voltages picked from the chest electrodes.

In $\mathrm{Q}$ wave patients, the presence of MI certainly causes local delay in the AP propagation and hence the time course of its propagation is a vital diagnostic aid in cardiac care.

At higher heart rates, the AP propagation time was not found by our measurements to decrease. Since it depends only on the anatomy of the ventricular fibers, MI causes AP delay which is almost the same even at higher heart rates. But, because of conduction contraction coupling, [9] fibrillation will set in with MI and high rates. A slow conducting segment will contract incongruously with the rest of the myofibers, leading to fibrillation. The AP propagation time measurement and its continuous trend observation will help a long way to avert events.

The paper is arranged as follows. The second section describes about our novel synchronous multiple lead recording. The third section describes the measurement circuitry using a PIC microcontroller on an LCD display. The fourth section provides some verification results. The conclusion states the points of importance and the usefulness of the technique for cardiology work.

\section{Material and methods}

\section{A. Simulating $Q$ waves from Action Potential waves}

In order to correlate the AP Time of propagation with the $\mathrm{Q}$ wave, an useful analysis was made in MATLAB. Figure 2 shows the torso and the typical electrode points from where the signal waves are picked up.

The action potential waveform has the following parameters:

1. Initial rise time $\mathrm{t}_{\mathrm{r}}$ (Mainly membrane dependent Capacitance)

2. Resting potential $\mathrm{p}_{\mathrm{r}}$ (Depends on external Sodium Concentration)

3. Peak potential $p_{1}$ (Depends on Potassium concentration inside to outside ratio)

4. Peak time $t_{p(m s)}$ (Depends on membrane recovery time for $\mathrm{K}^{+}$efflux)

5. Exponent decay of repolarization $\mathrm{t}_{\mathrm{cl}}$ (Calcium membrane recovery rate)

6. Calcium conducting time $\mathrm{t}_{\mathrm{CA}}$ (Amount of $\mathrm{Ca}$ ions in external fluid).

For instance, the data [40 -308520350 0.25] indicates $\mathrm{t}_{\mathrm{r}}=40 \mathrm{~ms}, \mathrm{p}_{\mathrm{r}}=-30 \mathrm{mV}, \mathrm{p} 1=80 \mathrm{mV}$ and so on for a typical action potential waveform.

The two waveforms at locations A and B are slightly different because:

I) The action potentials are locally generated signals in the cardiac fibers. There might be slight differences in the ionic concentrations locally. Therefore, the potentials differ.

II) The plateau period of the A.P. is dependent on Calcium concentration and also on the rate of contraction of that fiber. The distal fibers have shorter plateau period 


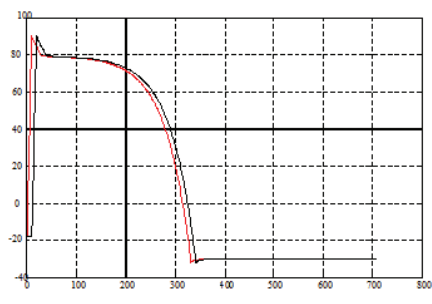

Figure 3. The action potentials waves at the two points A and B.

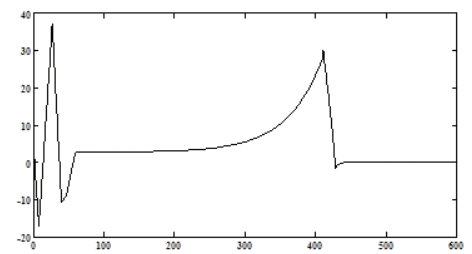

Figure 5. A Q wave is seen when the first parameter is changed forAP2.

and so the wave of A.P. at B restores to resting potential quicker.

III) The action potential wave is electro-tonically conducted from A to B. The rise of the A.P. at A is triggering the immediate fiber; this raises the threshold of membrane conductance change and at this immediately next fiber. That elicits an A.P. in that next fiber. In this manner, the entire path of fibrous tissue from point A to point B is triggered one after another. A time is taken for this and hence the start of the A.P. at B is delayed by the time taken for the electro-tonic conduction. There is a delay between the two waveforms shown at A and B.

Now let us assume that the voltage externally picked at electrode point 1 on the far away body surface is proportional to the voltage to the point $\mathrm{A}$ inside and that the voltage picked at body surface electrode point 2 is proportional to the voltage at point $\mathrm{B}$ inside.

It is true that the signal at 1 is not only due to that at $\mathrm{A}$ but also to that at $\mathrm{B}$. However, because 1 is near to $\mathrm{A}$, we get a better contribution from A than from B.

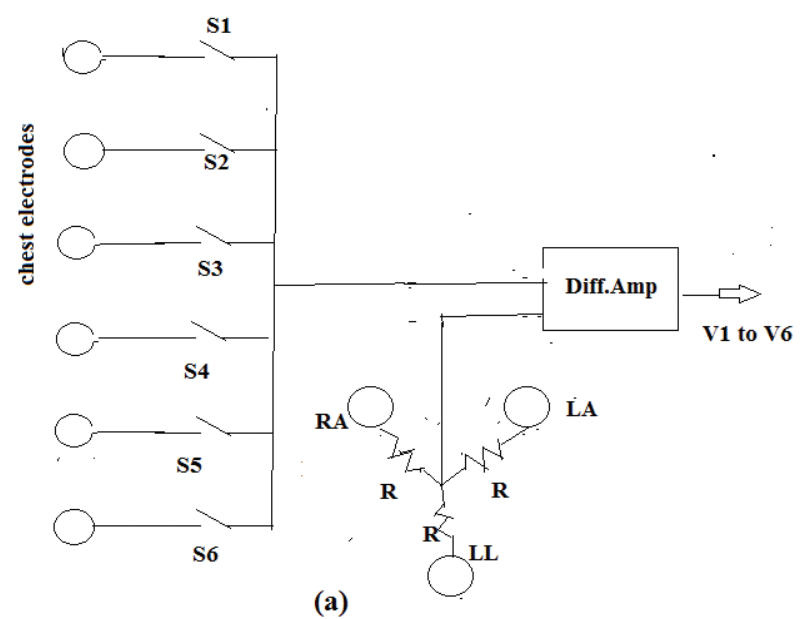

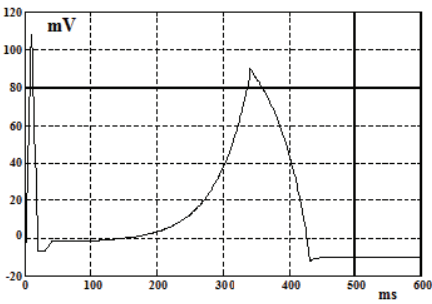

Figure 4. This is a typical ECG wave as usually seen in Lead I for normal heart.
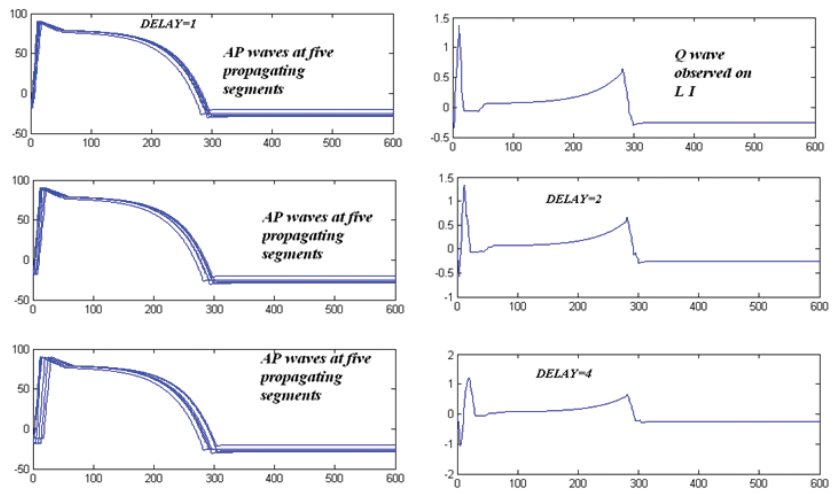

Figure 6 and $\mathbf{b}$. The left figures shows the AP waves at the sequential segments on the path A-B. The right figures deduce the ECG from the electrode voltages 1,2. Three delay values are assumed.

Thus, we can write

$$
e_{2}-e_{1}=G_{2} e_{B}-G_{1} e_{A}(2.1)
$$

The G's are the conductance's of tissue in between the body surface and points A, B. Points 1 and 2 are going to the amplifier inputs, which is a differential amplifier (Figure 3).

The subtracted waveform will be of the shape of the usual ECG between lead terminals 1, 2 (Figure 4).

There is no significant $\mathrm{Q}$ wave in the above Figure 4.

Rise time change en-route causes $\mathbf{Q}$ wave

A look at the simulated wave in figure below (Figure 5) is a clear example ECG (though sketchy) having a $Q$ wave.

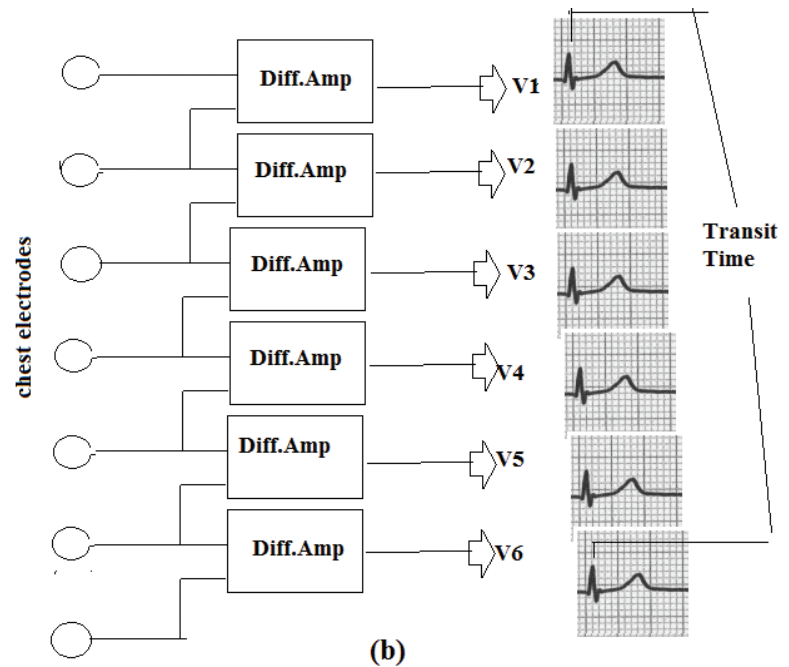

Figure 7. The use of multiple differential amplifiers along with EPIC electrodes 1 to 6 for transit time measurement. 
Its peak value is $40-45 \%$ of the $\mathrm{R}$ wave and hence is a pathology simulation. Let us now put down the simulation parameters, which gave rise to this figure.

Parameter for AP1 $=([40-3085203500.25])$;

Parameter for AP2 $=\left(\left[\begin{array}{ll}20 & -3085203800.21]\end{array}\right)\right.$;

Delay $=7 \mathrm{~ms}$ for AP2

Suppose we are to record ECG from a set of five electrodes placed on the chest from right to left, somewhat at equal distances. The five Action potential waves are assumed to have delays at the five segments on the path along the ventricular tissue as shown in Figure 6a. Conductance values are assumed from the segment sites to the electrode positions. The Figure $6 \mathrm{~b}$ shows this waveform, with the $\mathrm{Q}$ wave in it. As the delay increases, the $\mathrm{Q}$ wave width and depth both increase. This indicates how the AP propagation time is a more realistic measurement than the very small looking $\mathrm{Q}$ wave in the usual ECG records.

\section{B. Simultaneous multiple electrode recording}

So, if we have to measure the delay in propagation time over the entire ventricle, multiple electrodes must be placed on the chest wall and the difference voltages between them will show the time of propagation by the positions of the $\mathrm{R}$ wave peaks. For this purpose, all waveforms must be obtained from the same heartbeat, i.e., simultaneously. If we have to find out the said propagation time in one single beat, it will require multiple differential amplifiers (Figure 7). The outputs of these may then be compared by the time instants of the QRS peaks to recognize how the wave is propagating and initiating the action potentials through the ventricle.

We now describe the Synchronous Recording technique for measuring the time of propagation of the AP. To cite a previous reference, single action potential records from in vitro cardiac Purkinje fibers from sheep have been displayed with digital electronic circuitry [10] and the maximum rate of rise of the AP has been measured by McGillvray et al [11], but so far, non invasively, AP propagation time has not been measured with any instrument. This AP propagation time in a heartbeat in only between 15 to 20 milliseconds in the normal heart, while significant increase is related to conduction disturbances in the heart chamber due to infarction.

The electrode system for the purpose is also very simple, with six electrodes spread on the chest similar to the $\mathrm{V}$ leads and the 5 differential voltages are used to determine this time. The pathological Q waves in the ECG are the most often looked at patterns by the cardiologist. The increase in amplitude and width of this $\mathrm{Q}$ wave is associated with infarct tissue. The $\mathrm{Q}$ wave, as is being observed in standard ECG records, occupies just 1-2 mm of space horizontally and about $15 \mathrm{~mm}$ vertically. When it is required to check for improving heart conditions after a pathological Q wave, the same has to be carefully observed for very small changes in the width of it, which is after all, only 1 to $2 \mathrm{~mm}$ in the record. Thus, any improvement in the heart with drugs for blood thinning etc., cannot be noticed eas- ily. Since the Q wave is dependent only on the propagation time of the AP, it is much more useful if one could read the beat to beat propagation time. Changes from $30 \mathrm{~ms}$ little by little, down to $25 \mathrm{~ms}$, as the heart recovers, could be observed. This is useful to understand the efficacy of drugs administered in the care unit. An instrument of this kind has not been described or manufactured for cardiac care so far.

Usually, ECG waveforms for the Leads 1-3, the Auxiliary leads and the precordial leads are taken independently. Though these waveforms do not pertain to one and the same heart beat, the recorded waves indicate the pathology because there are not such fast changes in the beat to beat waveforms. The current ECG technique of recording with ECG Recording apparatus does not use simultaneous recording.

When we arrange all the $\mathrm{V}$ lead electrodes all at once on the chest and record the waveforms differentially from the sets of leads, we are able to do a synchronous recording. Such a recording from several leads is able to indicate the propagation of the $\mathrm{R}$ wave from one set of electrodes to another. Since the sharp rising $\mathrm{R}$ wave on the external skin electrode coincides with the first rise of the intracellular action potential, we could follow the propagation of the AP through the ventricle. By measuring the time difference between the $\mathrm{R}$ waves in the first and the last electrode, the propagation time is found. The value of this time is displayed directly in milliseconds, once in every two beats.

If the propagation of the AP is smooth and uniform throughout the ventricle with the same speed, then the time of propagation is not more than $15 \mathrm{~ms}$. In pathological cases, where there are conductance disturbances brought about by tissue damage, there is a local slowing down of the rise time of the AP in the damaged fibers and hence the overall time increases. In the case of patients with Right Bundle Branch Block (RBB), the time increases to more than $30 \mathrm{~ms}$.

Q waves with amplitude more than $1 / 4^{\text {th }}$ of the $Q R$ amplitude and wider than $15 \mathrm{~ms}$ appear when there is such delay in the AP propagation. Diagnosis presently relies more on the $\mathrm{Q}$ wave, as seen in its small graph. The AP transit time is a more realistic approach to such diagnosis.

The AP waveform is not exactly the same in all the fibers throughout the ventricle. The inner fibers from where the wave propagates have a longer plateau period. As the wave progresses into the ventricular tissue, the main variations in the AP are in the plateau period and the depolarization time. These variations affect the ST segment slope and the $\mathrm{T}$ wave. Simultaneous recording from all electrodes can elicit information about the place of such conditions which cause a drooping $\mathrm{T}$ wave and hence an ST elevation.

If the propagation does not meet with infarct tissue, then the time between the electrodes is uniformly increasing; otherwise, a sudden increase of time between $\mathrm{R}$ waves 
of two adjacent electrodes indicates pathological problem local to these electrodes. Thus, where the time exceeds nominal $20 \mathrm{~ms}$ values, it is necessary to note the timings between all the electrode pairs, 1-2, 2-3, 3-4, 4-5, 5-6.

Then the differential voltages from these electrodes in the order 1-2, 2-3, 3-4, etc., were taken and observed on a multiple channel Agilent make digital storage oscilloscope. It was by taking the recorded digital values form it through its USB to the computer laptop and through Matlab programs, that we could get the displays and enumerate the time between the several wave peaks of QRS as well as the time course of propagation of the action potential from right side to the left side of the heart.

It was very soon realized that it would be more useful if an on-line continuous indication of the time course of action potential through the heart in several sections from right to left could be provided as an adjunct to the actual ECG wave records.

In a heart with a RBB, the time is slow initially but further to the bundle branches, the AP propagation is very fast. In other words, by looking at these intermediate timings, it is possible to assess where the pathological problem of ischemic tissue or infarct area is likely to be and what could be the artery on the heart that might have led to this condition.

\section{Electrode set up for the Measurement}

Electrodes and pre-amplifiers for ECG have long been under development to provide patient comfortable signal acquisition. For instance, a ground-free multichannel amplifier with a simple 2 electrode bio-amplifier is described in [12].

Plessey Microelectronics has brought out sensor electrodes for use as ECG electrodes recently [13]. These electrodes do not need the presently employed contact resistance reducing jelly. Such a jelly is usually applied to ECG electrodes on the skin. This sensor (Figure 8) couples the signal capacitively and hence a mere placement on the skin surface firmly is sufficient without any applied jelly. Jelly pastes applied to skin lower the contact resistance very much and lead to the possibility of electric shock in case of faults in monitoring apparatus connected to the care patient. Because the Plessey electrodes use capacitive coupling, they are high impedance contacts and are free from such electric shock. Further, the Plessey electrode is not just a contacting metal plate like the present ECG electrodes. This is actually an integrated circuit chip directly held on the skin and includes the pre-amplifier with its high input impedance and high common mode rejection ratio built into it. Thus, with these Plessey electrodes, it is much easier to pick the ECG signal and amplify it further with a simple differential amplifier. Instead of special FET input balanced circuits at the input end, an ordinary OPAMP suffices because the output impedance of the EPIC sensor is low.

Yet another usefulness of these electrodes is that several chips can be closely kept on the skin, as is done for taking

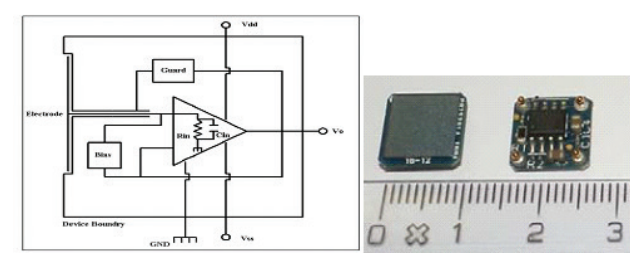

Figure 8. Plessey "EPIC" Capacitive ECG Micro Electrode and its internal schematic diagram.

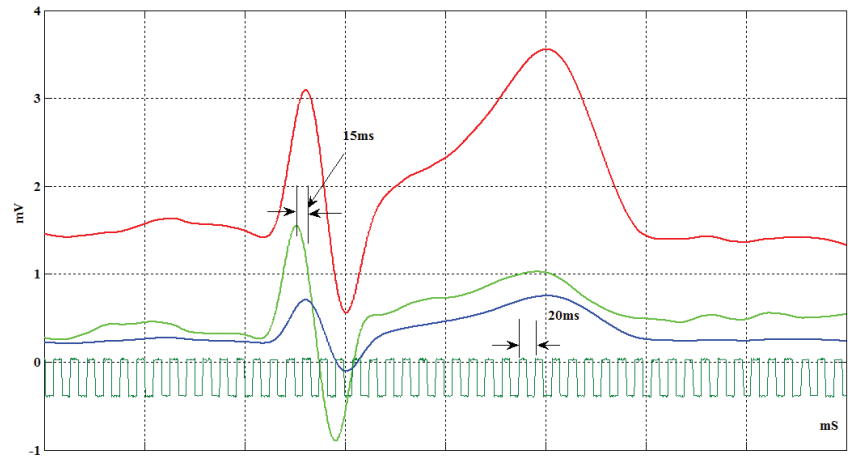

Figure 9. Showing a patient Action potential propagation by means of three differential electrode voltages from right to left. This is a case of slight ST elevation with a time of $15 \mathrm{~ms}$.

V-lead signals. With jelly contact, there will be jelly spreading, causing a short circuit if electrodes are closely spaced on the chest skin. Further, as no jelly at all is required here, we need not prepare the surface of the skin before placing the electrodes.

We could place several electrodes all at the same time and the simultaneous ECG records from all of them could be taken.

By using several electrodes spread on the chest from right to left, similar to the $\mathrm{V}$ leads though not exactly at the specific locations for $\mathrm{V}$ leads, we were able to record the ECG signals differentially. At first we employed a multi channel Digital Storage Scope for the purpose which was adjusted to take 5 Kilosamples of data on all channels per second so that the fine tips of the $\mathrm{R}$ wave could be collected. The DSO data was collected through its USB support and transferred to a laptop computer running Matlab 2012.

From $Q$ wave observations, small changes in pathology cannot be inferred; but with this time measurement, which will change slowly in a progressively deteriorating or convalescing heart, the same can be measured with an accuracy of $0,1 \mathrm{~ms}$.

For illustration, two such graphs are shown below. The first one is that of a patient with mild ST elevation and the time of APP is indicated as $15 \mathrm{~ms}$ (Figure 9).

As another illustration, the Figure 10 gives a $35 \mathrm{~ms}$ delay for the patient who has noted $\mathrm{Q}$ wave. The three graphs shown pertain to the three leads from right to left of the chest. It may be noted that the half width of the $\mathrm{Q}$ wave is also of the same time as the Time of Action potential Propagation. 


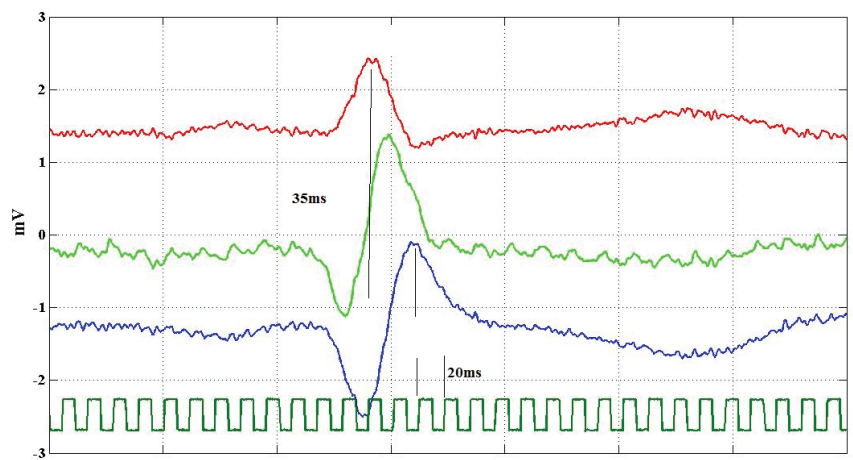

Figure 10. This figure is that of a heart with $Q$ wave pathology (NSTEMI) and shows 35 ms delay.

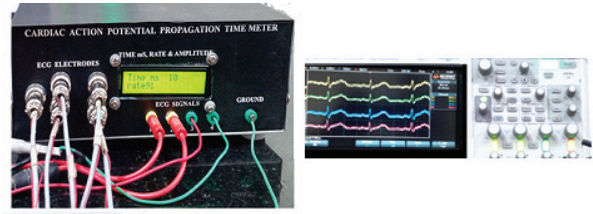

Figure 11. The instrument shows the time of APP. Electrodes to chest are taken from connectors on the left and the amplified signals can be taken for observation from the sockets "ECG Signals". The Digital Storage scope shows the waveforms.

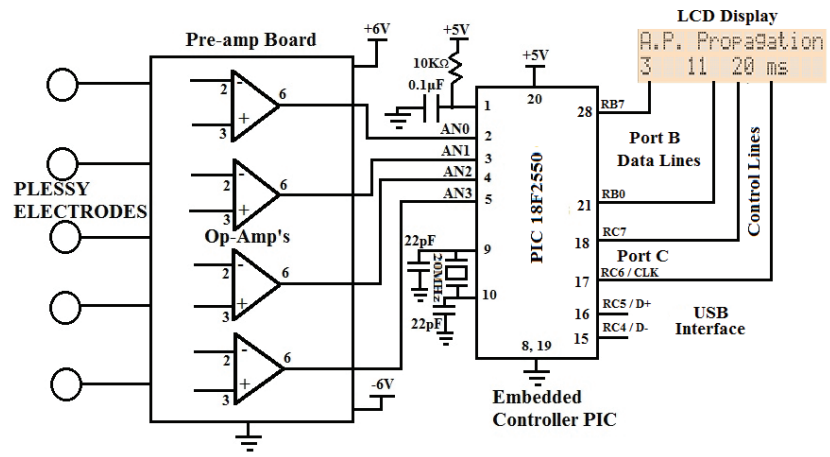

Figure 12. The use of an embedded controller could display the propagation timings.

D. Measurment and on line continuous display of action potential propagation time

Figure 11 shows the instrument as such. The signals from five such sensor pads are connected to four operational amplifiers for differential amplification (Figure 12). Thus, we obtain four signals, with an amplification of 500 for each. These signals are connected to a four channel digital scope. Further, these signals are also connected to the analog to-digital converters on the PIC18F2550 microcontroller. The ADCs in it can be operated at 50 microsecond per sample. The values of the four channels are processed by the embedded controller to determine the QRS peak of each of the signals. To eliminate the effect of base line drift, in addition to finding the peak of the signal, the first derivative of the signal is also found between successive samples and the maximum point of the derivative is also found for all the four signals. If the two timings, viz.,
Table 1

The flow chart of the program with the embedded microcontroller

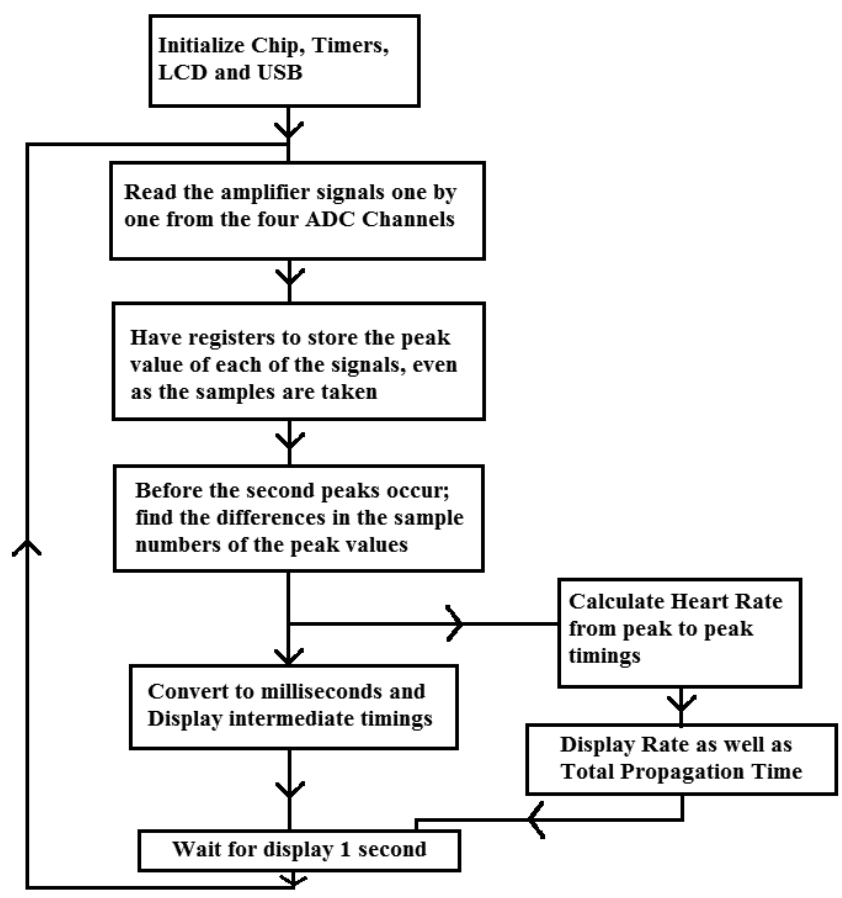

Table 2

Some clinical tests on cardiac patients

\begin{tabular}{|l|l|l|}
\hline Pathology as per ECG of patients & No. of patients examined & APP TIME \\
\hline T- inversion & 4 & $10-15 \mathrm{~ms}$ \\
\hline RBB with Mild Q & 7 & $30-40 \mathrm{~ms}$ \\
\hline RBB without Q & 15 & $20-25 \mathrm{~ms}$ \\
\hline STEMI & 7 & $25-30 \mathrm{~ms}$ \\
\hline NSTEMI & 5 & $30-45 \mathrm{~ms}$ \\
\hline
\end{tabular}

the time of the recognized peak and the time of the maximum rate of change coincide, then the readings are assessed to be correct and the time differences between the signals are calculated based on the sampling rate. These are the three time values which are displayed on line in the LCD alphanumeric display connected to the embedded controller circuit. The display is updated every five seconds and hence changes in the timings, if found to be progressively increasing or improving, can be used for diagnosis of the condition of the heart.

The program for the PIC18F2550 to perform this task and provide an on line display of the propagation was developed using the the powerful OSHON simulator for PIC18 Series [15]. The flow chart of the program is shown in table I.

It is normally thought that at an increased heart rate, say from 72 to 100 , the timings will decrease proportion- 
ately. But it was found that the rate does not relate to the timing of the propagation of the action potential. The timing is very small compared to the sinus rhythm which causes the heart beat to vary and hence there is not much change even at a higher rate of heart beat.

The following description is given for the electronic enthusiasts about the circuit. The PIC18F2550 series is a Microchip Inc. make embedded controller with $20 \mathrm{MHz}$ clock and built in peripherals like PWM,ADC UART and USB interface. The chip has an excellent reset circuit and operates with power on reset action, for which a resistor of $10 \mathrm{k}$ and a $0.01 \mathrm{uF}$ capacitor are connected to pin no.1. Pins of port A, from 2 to 6 are configured by a command code to operate as analog to digital converter input pins. The reference voltage pin can be given a voltage different from the $5 \mathrm{~V}$ supply of the chip and by giving $2 \mathrm{~V}$ as a reference, the range of digital values will be 0 to 255 for $0-2 \mathrm{~V}$. The operational amplifiers used with the Plessey electrodes are simple 741 devices. The power supplies for the OPAmp are obtained from two $6 \mathrm{~V}$ batteries, rather than mains derived supplies, so as to eliminate hum completely. From these same $6 \mathrm{~V}$ batteries, through a resistor pair, the + and $-5 \mathrm{~V}$ supplies for the Sensor electrodes are derived and limited by $5 \mathrm{~V}$ zener diodes. The PIC chip being connected through USB to a lap top computer, gets its supply of $5 \mathrm{~V}$ from the latter. The laptop is kept pre-charged and unplugged from mains for safety while connecting electrodes to the chest. Apart from the analog input signal connections, the PIC chip is connected to an alphanumeric two row LCD display. This needs 8 data lines and four control lines, which are available as shown in the Figure 13 from the chip ports B and C. Additionally one bit of port $\mathrm{C}$ is programmed and taken to an output pin. It provides a pulse at each and every data acquisition sample period. This serves to calibrate the timing of the QRS peak displacements while setting up. After noting this time period, the actual timings are evaluated in milliseconds and displayed on the two rows of the LCD.

\section{Results}

Cardiac Care outpatients at the nearby Hospital were tested with their consent by placing the EPIC electrode strip on the chest and the time of Action Potential Propagation (APP) measured. Their ECG records and previous medical reports were also noted. From the set of tests, the following table verifies that concept.

Patients with long standing myocardial infarction were those who had the $\mathrm{T}_{\mathrm{APP}}$ prolonged to as much as $40 \mathrm{~ms}$. They are classified as non ST elevation myocardial infarction candidates (NSTEMI) as per diagnostic parlance. Those who had recent MI with ST elevation (STEMI) had also long $\mathrm{T}_{\mathrm{APP}}$ upto $30 \mathrm{~ms}$.

As far as patients with known conductance disturbance with or without $\mathrm{Q}$ wave of significance, the time delay due to Bundle Branch Block pathology gives readings in the 20-25 ms for those without Q waves and 30-40 ms with

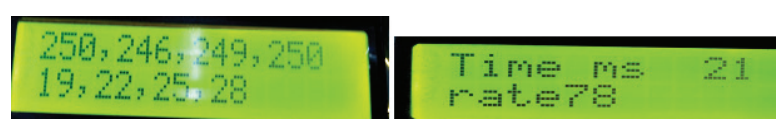

Figure 13. The Mode I display shows the four QRS peak values and the corresponding timings in ms. In mode II of display, it shows the total AP Propagation time and the heart rate.

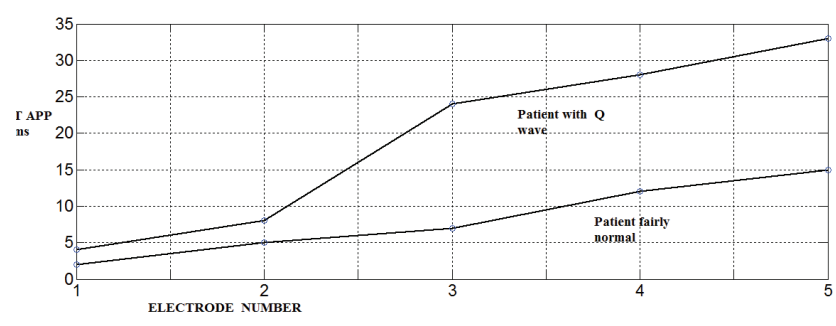

Figure 14. Showing the delays between Electrodes 1 to 5 as they are placed in the precordial lead positions for fairly normal heart and one with MI.

those who have an associated infarction at the time of their heart attack. Patients with T wave inversion are not gullible at all because $T$ wave inversion due to Ischemia does not very much increase the $\mathrm{T}_{\mathrm{APP}}$ Thus from a group of patients, thus far it is learnt that the $\mathrm{T}_{\mathrm{APP}}$ will increase in the case of infarction and RBB and is a more decisive parameter for pathological classification than $\mathrm{Q}$ waves.

By plotting the intermediate timings as shown in the insert figure (LCD Display) of Figure 14, a plot could be made to show how the AP propagates. Because it is impossible to position the electrodes with a uniform mapping of the heart by external placement, the line joining the intermediate delay is somewhat skewed and not a straight line. But, the location where the time delay is present is indicated in the above figure for a patient with $\mathrm{Q}$ wave, as between the mapping positions of electrodes 2 and 3 .

\section{Conclusion}

We have realized a method for synchronous recording of ECG waveforms and used the same to evaluate the time of propagation of the Action potential in the ventricles. The EPIC microelectrodes are a boon because of their no-jelly contacts makes it instantly possible to fix the electrodes and observe the reading of time of APP with the least patient discomfort. It also eliminates the complex differential amplifiers normally used for high CMRR and input impedance. The time of action potential is measured on our simple embedded controller. Cardiac monitor makers could include this in their own hardware and display this AP propagation time for good. The usefulness of this time in cardiac diagnosis has been stressed in the paper.

Acknowledgment. The experimental data shown were collected from the Vadapalani Multi-Speciality Hospital, Chennai with individual permissions from the patients. 


\section{References}

1. Ananthi S. Medical Instruments, New Age International Publishers, 2005

2. Daskalov IK, Christov II. Automatic Detection of ECG T wave end, Med.\& Biol. Engg. and Computing, 1999:37348-54.

3. Laguna P, Jana R, Olmos S, et al. Adaptive Estimation of QRS Complex Wave Features of ECG Signal, Med, \&Biol. Engg. and Comp., Jan. 1996: 58-63.

4. Padmanabhan K. Circuit to Explain Cardiac Conduction and Propagation, Med. \& Biol. Engg and Control, 1977, 15, 604-610.

5. Stephen Rohr, Role of Gap Junctions in the Propagation of Cardiac Action Potential, Cardiovasc. Res., May 2004.

6. Yan Wang, Yoram Rudy, Action Potential Propagation in in Homogeneous Tissue: Safety Factor and lonic Disturbances, Am.Jour. Physiol. Heart and Circ., 2000(4), 278.

7. $Q$ wave and Non $Q$ Wave Myocardial Infarction - A Multivariate Analysis, Jour. Pak. Med. Assn., June 1999, p.149-154.

8. Mathhlas Goernig, Benjamin Hoeffling et al, T-Vector and Loop Characteristics Improve Detection of Myocardial Injury After Infarction, Med. \& Biol. Engg. and Comp., 2015: 381-6.

9. Padmanabhan K, Ananthi S. Analysis of Fibrillation and Defibrillation to Develop Minimal Energy Defibrillator, Jour. Inst.Engrs.(India), 2008; 89(5).

10. Waxman MB, Berman ND, Downer E. A Method for On-Line Automatic Beat to Beat Digital Display of Cardiac Action Potential Duration, Med. \& Biol. Eng. and Control., 1976.

11. McGillvray RM, Wald RW. Measurement of the Maximum Rate of Rise of the Cardiac APMed. \& Biol.Engg. and Comp. 1984.

12. Dobra D, Neycheva T, Mudrov N. Simple Two Electrode Biosiganl Amplifier Med. \& Biol. Engg. and Computing, 2005 (43), 725-30.

13. Plessey EPIC Micro Electrodes, Plessey Inc., 2013.

14. Wang AY, Rudy Y. Action Potential Propagation in Homogeneous Tissue: Safety Factor and Ionic Disturbances, Am. Jour. Physiol. Heart and Circ., 2000(4), 278.

15. www.oshon.com. 